\title{
Analyst
}

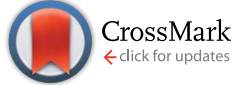

Cite this: Analyst, 2014, 139, 5885

Received 18th February 2014 Accepted 3rd September 2014

DOI: $10.1039 / c 4 a n 00345 d$

www.rsc.org/analyst

\section{Rapid and simultaneous detection of ricin, staphylococcal enterotoxin B and saxitoxin by chemiluminescence-based microarray immunoassay $\dagger$}

\author{
A. Szkola, ${ }^{a}$ E. M. Linares, ${ }^{a}$ S. Worbs, ${ }^{\text {b }}$ B. G. Dorner, ${ }^{\text {b }}$ R. Dietrich, ${ }^{c}$ E. Märtlbauer, ${ }^{c}$ \\ R. Niessner ${ }^{a}$ and M. Seidel ${ }^{\star a}$
}

Simultaneous detection of small and large molecules on microarray immunoassays is a challenge that limits some applications in multiplex analysis. This is the case for biosecurity, where fast, cheap and reliable simultaneous detection of proteotoxins and small toxins is needed. Two highly relevant proteotoxins, ricin $(60 \mathrm{kDa})$ and bacterial toxin staphylococcal enterotoxin $\mathrm{B}(\mathrm{SEB}, 30 \mathrm{kDa})$ and the small phycotoxin saxitoxin (STX, $0.3 \mathrm{kDa}$ ) are potential biological warfare agents and require an analytical tool for simultaneous detection. Proteotoxins are successfully detected by sandwich immunoassays, whereas competitive immunoassays are more suitable for small toxins $(<1 \mathrm{kDa})$. Based on this need, this work provides a novel and efficient solution based on anti-idiotypic antibodies for small molecules to combine both assay principles on one microarray. The biotoxin measurements are performed on a flow-through chemiluminescence microarray platform MCR3 in 18 minutes. The chemiluminescence signal was amplified by using a poly-horseradish peroxidase complex (polyHRP), resulting in low detection limits: $2.9 \pm 3.1 \mu \mathrm{g} \mathrm{L}^{-1}$ for ricin, $0.1 \pm 0.1 \mu \mathrm{g} \mathrm{L}^{-1}$ for SEB and $2.3 \pm 1.7 \mu \mathrm{g} \mathrm{L}^{-1}$ for STX. The developed multiplex system for the three biotoxins is completely novel, relevant in the context of biosecurity and establishes the basis for research on anti-idiotypic antibodies for microarray immunoassays.

\section{Introduction}

Biotoxins are substances produced by microorganisms, fungi, plants or animals, which cause harmful effects on other organisms. They include a variety of substances ranging from $0.14 \mathrm{kDa}$ to $150 \mathrm{kDa}$ in molecular weight $(\mathrm{Mw}) .{ }^{1}$ Their toxicity depends on the dose, the application route and the specific mechanism of action within the organism. The existence of highly toxic biotoxins makes them powerful candidates for being used as biological warfare agents. ${ }^{2}$ Among the highly toxic lectins, ricin $(60 \mathrm{kDa})$ is considered a potential biological weapon due to its low lethal dose $\left(\mathrm{LD}_{50}: 3 \mu \mathrm{g} \mathrm{kg}{ }^{-1}\right)$; accidental and intentional intoxications using ricin have been reported. ${ }^{3}$

${ }^{a}$ Chair for Analytical Chemistry \& Institute of Hydrochemistry, TU München, Marchioninistrasse 17, 81377 Munich, Germany. E-mail: michael.seidel@ch.tum.de; Fax: +49 (89) 2180-78255; Tel: +49 (89) 2180-78238

${ }^{b}$ Centre for Biological Threats and Special Pathogens, Biological Toxins, Robert KochInstitut, Nordufer 20, 13353 Berlin, Germany

'Chair of Hygiene and Technology of Milk, LMU München, Schönleutnerstraße 8/219, 85764 Oberschleißheim, Germany

$\dagger$ Electronic supplementary information (ESI) available: ESI S1 Experimental details; S2 comparison between horseradish peroxidase-streptavidin (SA-HRP) and poly(horseradish peroxidase)-streptavidin (SA-PolyHRP40); S3 influence of the sequential and parallel addition of reactants; S4 influence of the flow rate and interaction time on the CL signal. See DOI: 10.1039/c4an00345d
Ricin is produced in seeds of castor oil plant ${ }^{4}$ and consists of a heterodimeric glycoprotein. ${ }^{5}$ It is an attractive biotoxin for potable water supply and food processing due to the easy extraction from the plant and the resistance to chlorination and disinfection methods. Together with ricin, saxitoxin $(0.3 \mathrm{kDa}$, STX) is listed in the Chemical Weapon Convention ${ }^{6}$ and in the War Weapon Control Act, safety category B. ${ }^{7}$ Saxitoxin is a neurotoxin produced by cyanobacteria and dinoflagellates and consists of a highly polar alkaloid. ${ }^{8,9}$ Due to its high toxicity $\left(\mathrm{LD}_{50}: 10 \mu \mathrm{g} \mathrm{kg}^{-1}\right)$ and stability, saxitoxin has also high potential as a biowarfare agent, only limited by difficult synthesis. ${ }^{\mathbf{1 0 , 1 1}}$ Another powerful toxin and possible agent biowarfare is the staphylococcal enterotoxin B (30 kDa, SEB) produced by a grampositive and facultative anaerobic bacterium, Staphylococcus aureus. SEB is a protein with no potential for high mortality, but its high emetic potency $\left(\mathrm{LD}_{50}: 0.02 \mu \mathrm{g} \mathrm{kg}{ }^{-1}\right.$ ) and fast action ( 2 to $8 \mathrm{~h}$ ) raised an interest as incapacitating agent. ${ }^{12,13}$ SEB has high stability even resisting a few minutes at temperatures above $100{ }^{\circ} \mathrm{C}$ and is frequently involved in food poisoning outbreaks. ${ }^{\mathbf{1 4}}$

The use of biotoxins as biological weapon displays a permanent risk for humans. ${ }^{15}$ The described biotoxins are relatively easy to spread, causing moderate to high mortality. Due to their characteristics, these toxins are probable candidates for a warfare use and therefore need to be verified in case 
of terrorist attack suspicion. This potential risk leads to a demand on the simultaneous diagnosis of the biotoxins by a fast, cheap and reliable assay. Different techniques have been described to detect those toxins, ${ }^{3,16}$ including chromatography, ${ }^{17}$ spectrophotometry, ${ }^{18,19}$ mass spectrometry, ${ }^{20,21}$ electrochemistry, ${ }^{22}$ as well as assays addressing functional activity. ${ }^{23}$ While a wide range of methods is used, many assays rely on immunological detection of target molecules due to the high specificity and sensitivity. ${ }^{31}$ Microarray immunoassays (MIAs) in particular have gained attention, as they benefit of the capability to test a wide variety of analytes in a single assay, reducing time of analysis and costs. ${ }^{32}$ MIA for biotoxins is a promising tool for the identification and detection of an eventual contamination and different approaches have been described in the literature. ${ }^{33-35}$ An overview of recent detection limits for biotoxins in microarrays is given in the Table 1 .

Although some microarrays have been successfully developed, a few challenges still need to be faced according to the broad diversity of samples and particularities of each biotoxin. In order to overcome these problems, different approaches have been described combining different assay principles on the microarray. Hartmann et al. ${ }^{36}$ described a novel assay format that combines competitive and direct immunoassay principles into one system to overcome dilution sample problems of proteins. Molecules present in high concentrations as well as those occurring at low concentrations could be quantified within the same assay. A greater challenge is the wide range of molecular weight. Small molecules with less than $1000 \mathrm{Da}$ in molecular weight are not considered amenable to sandwich immunoassays due to their difficulty of simultaneous recognition by two antibodies. ${ }^{37}$ In this case, other arrangements can be used, including competitive assays. Parro et al. ${ }^{38}$ and Fernández-Calvo et al. ${ }^{39}$ described the development of protein microarray technologies for automatic in situ detection and identification combining sandwich and competitive immunoassays. The assay was developed to analyze liquid and solid samples from extraterrestrial origin, ranging from small molecules and proteins to whole cells and spores. Although the direct immobilization of analytes on the microarray for the competitive assay was successfully performed, this is not always the case. There are small molecules whose structure does not have enough functional groups for immobilization or are not available in the required amounts. ${ }^{40}$ In this case, the immobilization may affect the antibody recognition, the regenerability of the microarray or does not provide concentrated spots, as already described for STX. ${ }^{29}$ Additionally, the direct immobilization of molecules on the microarray may require previous coupling to other larger molecules (e.g. albumin) or different chemical functionalities on the microarray surface, which increases the work and cost of production.

Based on this challenge, this work describes the development of a microarray for ricin, SEB and STX detection, combining sandwich and indirect competitive immunoassays in one platform. The combination of both methods is possible through the use of anti-idiotypic antibodies for small molecules. These antibodies are immunoglobulins, whose paratope mimics the structure of an antigen and recognize the epitopes of the antibody produced for the antigen. ${ }^{41}$ It represents a powerful alternative for direct immobilization of small molecules, in this case STX, on the microarray. The proteotoxins, ricin and SEB, are detected using sandwich based immunoassay, where labeled antibodies bind to the antigen and the antibody-antigen pairs are captured by the immobilized antibodies. For STX detection, a competition between its labeled antibodies and the immobilized anti-idiotypic antibodies take place on the chip. Thus, it is produced a microarray containing anti-idiotypic antibodies for STX and conventional antibodies for ricin and SEB. This strategy avoids the need of analyte coupling to large molecules or different surface chemistry for immobilizing antibodies and analyte on the same microarray surface. The microarray is placed in an automated system, the Munich Chip Reader (MCR3), which allows precise and fast onsite analysis. For the first time, MIA is capable to detect proteotoxins and small toxins, simultaneously. The microarray can be used as a tool for monitoring biotoxins in samples as a preventive protection of the population against natural or deliberate contaminations. Moreover, this technology shows the potential of anti-idiotypic antibodies for the simultaneous detection of small and large molecules on the same microarray.

\section{Materials and methods}

\section{Chemicals and materials}

Di-potassium hydrogen phosphate, di-sodium hydrogen phosphate, sodium hydroxide, absolute ethanol 99.8\%, $\mathrm{N}, \mathrm{N}$-dimethylformamide (DMF), di( $N$-succinimidyl) carbonate (DSC),

Table 1 List of LOD for ricin, SEB and STX in microarrays recently described in the literature

\begin{tabular}{llll}
\hline Biotoxins & Application & $\begin{array}{l}\text { Limit of detection } \\
\left(\mu \mathrm{g} \mathrm{L} \mathrm{L}^{-1}\right)\end{array}$ & Type of detection \\
\hline Ricin & Biosecurity & 0.1 & Antibody/fluorescence \\
SEB & & 0.01 & \\
Ricin & Food safety & 0.5 & Antibody/fluorescence \\
SEB & & 0.5 & \\
Ricin & Protein screening & 15 & Aptamer/fluorescence \\
Ricin & Biosecurity & 80 & Carbohydrate/chemiluminescence \\
SEB & Proof of principle for microarray development & $3.10-6$ & 24 \\
STX & Food safety & 0.4 & Antibody/electrochemistry \\
STX & Food safety & 0.82 & Antibody/chemiluminescence \\
& & & Antibody/surface plasmon resonance
\end{tabular}


4-dimethylaminopyridine (DMAP), anti-rabbit HRP, ethylenediamine, 3-glycidyloxypropyltrimethoxysilane (GOPTS), $3,3^{\prime}, 5,5^{\prime}$-tetramethylbenzidine potassium hydrogen phosphate (TMB), pluronic F127, D(+)-trehalose dihydrate, casein, sodium chloride were obtained from Sigma-Aldrich (Taufkirchen, Germany). Sulfo-NHS-LC-biotin and Hellmanex were obtained from Fisher Scientific (Schwerte, Germany) and Hellma $\mathrm{GmbH}$ (Mannheim, Germany), respectively. Jeffamine ED-2003 polyetheramine was obtained from Huntsman (Salt Lake City, USA). Westar supernova ELISA luminol and hydrogen peroxide were purchased from Cyanagen (Bologna, Italy). The ARcare 90106 adhesive film was obtained from Adhesive Research Ireland (Limerick, Ireland). The poly(methyl methacrylate) support for the chip was produced in our laboratory. The glass slides $(76 \mathrm{~mm} \times 26 \mathrm{~mm} \times 1 \mathrm{~mm})$ were purchased from Carl Roth (Karlsruhe, Germany). Microplates with 96- and 384-wells were obtained from Greiner GmbH (Frickenhausen, Germany).

Mouse monoclonal antibody $(\mathrm{mAb})$ production against ricin (R109, R18, R21) and SEB (S1001, S419) was described elsewhere. $^{31}$ Clone S3849 against SEB was produced similarly. Highly purified agglutinin and ricin were produced as described. ${ }^{42}$ Anti-idiotypic antibodies from mouse mAb 1F8, anti-STX from mouse mAb 7H11 and biotinylated anti-STX from mouse mAb 7H11 were obtained from the Chair of Hygiene and Technology of Milk (LMU Munich, Germany). Anti-idiotypic antibody production and antibody biotinylation are described in more details in the ESI (S1 $\dagger$ ). HRP-labeled streptavidin was purchased from Axxora Germany GmbH (Lörrach, Germany). Horseradish peroxidase (HRP) was purchased from Roche Diagnostics GmbH (Mannheim, Germany). Saxitoxin (STX) was obtained from Institute of Agri-Food and Land Use (Belfast, Ireland). Staphylococcus enterotoxin B (SEB) was purchased from Diavita GmbH (Heidelberg, Germany). Poly(horseradish peroxidase)-streptavidin (SA-PolyHRP40) was obtained from Senova GmbH (Jena, Germany).

\section{Glass slide and microarray preparation}

Before antibody immobilization, glass slides were treated and functionalized according to procedures described elsewhere. ${ }^{\mathbf{4 3 4 4}}$ The microarray preparation was performed as described in Wolter et al. ${ }^{43}$ More details are described in the ESI $(\mathrm{S} 1 \dagger)$. The spots were produced using the Spotter BioOdyssey Calligrapher MiniArrayer from Bio-Rad Laboratories $\mathrm{GmbH}$ (Munich, Germany). The solid pin SNS 9 was purchased from ArrayIt (Sunnyvale, USA).

\section{Measurement of the antibody microarray with MCR3}

The microarray was connected to the fluidic system of the microarray analysis platform in the MCR3 from GWK Präzisionstechnik (Munich, Germany). More details are described by Kloth et al. ${ }^{45}$ and in the ESI, S1. $\dagger$ An aliquot of 0.3 $\mathrm{mL}$ of standard solution or sample was placed in the incubation loop of the MCR3. Then, $0.7 \mathrm{~mL}$ of standard or sample was mixed with $0.7 \mathrm{~mL}$ of detection antibody solution. The antibodies were used in the following concentrations: anti-ricin R18 $1.6 \mathrm{mg} \mathrm{L}^{-1}$, anti-SEB $4190.5 \mathrm{mg} \mathrm{L}^{-1}$, anti-STX mAb 7H11
$0.1 \mathrm{mg} \mathrm{L}^{-1}$. The concentrations were previously optimized for each antibody. This mixture was pumped into the $50 \mu \mathrm{L}$ unit with a flow rate of $10 \mu \mathrm{L} \mathrm{s}^{-1}$ and an interaction time of $10 \mathrm{~s}$ in the flow cell. The chip was then washed with $2 \mathrm{~mL}$ of PBST (10 $\mathrm{mM} \mathrm{KH}_{2} \mathrm{PO}_{4}, 70 \mathrm{mM} \mathrm{K} \mathrm{HPO}_{4}, 145 \mathrm{mM} \mathrm{NaCl}$ with $0.05 \%$ of Tween $20, \mathrm{v} / \mathrm{v}$ ) at $500 \mu \mathrm{L} \mathrm{s}{ }^{-1}$. Subsequently, $1 \mathrm{~mL}$ conjugate solution (SA-PolyHRP40 $1 \mathrm{mg} \mathrm{L}^{-1}$ ) was added in two portions into the flow cell: $200 \mu \mathrm{L}$ at $100 \mu \mathrm{L} \mathrm{s}^{-1}$ and $800 \mu \mathrm{L}$ at $5 \mu \mathrm{L} \mathrm{s}^{-1}$. After a further washing step with PBST ( $2 \mathrm{~mL}$ at $500 \mu \mathrm{L} \mathrm{s}^{-1}$ ), $250 \mu \mathrm{L}$ of luminol and hydrogen peroxide were simultaneously added into the flow cell with a flow rate of $10 \mu \mathrm{L} \mathrm{s}{ }^{-1}$. The CL signal was recorded for $60 \mathrm{~s}$ with a CCD camera. After the image acquisition, the microarray was rinsed with PBST buffer $(2 \mathrm{~mL}$ at $500 \mu \mathrm{L} \mathrm{s}^{-1}$ and $3 \mathrm{~mL}$ at $250 \mu \mathrm{L} \mathrm{s}^{-1}$ ). The total running time of the assay was $18 \mathrm{~min}$. The background image is previously recorded before the standard solutions or samples are added to the microarray. The optimizing experiments were performed only once and the error bars are the average of five spots. The calibration curves were measured three times with different microarray chips; hence the error bars are the standard deviation of 3 values obtained by the average of five spots per chip. The limit of detection (LOD) was calculated by the blank average plus three times the standard deviation of the blank. The three toxins are listed by the U.S. Department of Health and Human Services (HHS) as "HHS select agents and toxins", which affect humans. During the experiments, samples were handled in a extractor hood and waste was collected separate from usual waste (solid waste was deactivated with $5 \% \mathrm{NaOH}$ and liquid waste was deactivated with $5 \% \mathrm{NaOH}$ and then autoclaved for 1 $\mathrm{h}$ at $\left.121^{\circ} \mathrm{C}\right)$.

\section{Results and discussion}

\section{Assay principle}

To perform a multiplex immunoassay with different molecular weight biotoxins, an antibody microarray is designed and produced by the immobilization of anti-ricin and anti-SEB capture antibodies on the glass slide with anti-idiotypic antibodies for STX, as observed in Fig. 1a.

Prior to the detection, the biotinylated antibodies and the biotoxins are incubated together to promote the interaction between the respective antigen-antibody pairs. This step is especially important for the competitive assay for STX detection.

On the microarray, the pairs of antibody-biotoxin bind to the respective capture antibodies for ricin and SEB, producing a sandwich. In contrast, the detection of STX occurs through a competition between the free STX molecules and the immobilized anti-idiotypic antibodies to the biotinylated anti-STX antibodies. The detection signal is provided by enzyme catalyzed chemiluminescence reaction with luminol and hydrogen peroxide, using peroxidase-streptavidin conjugates. The signal for ricin and SEB are directly proportional to the biotoxin concentrations. For STX, the chemiluminescence intensity is inversely proportional to the concentration of the antigen. The pre-incubation of the biotinylated antibodies with the biotoxins is performed by the injection of the solutions into the loop of the MCR3 system (Fig. 1b). The solution is then automatically 


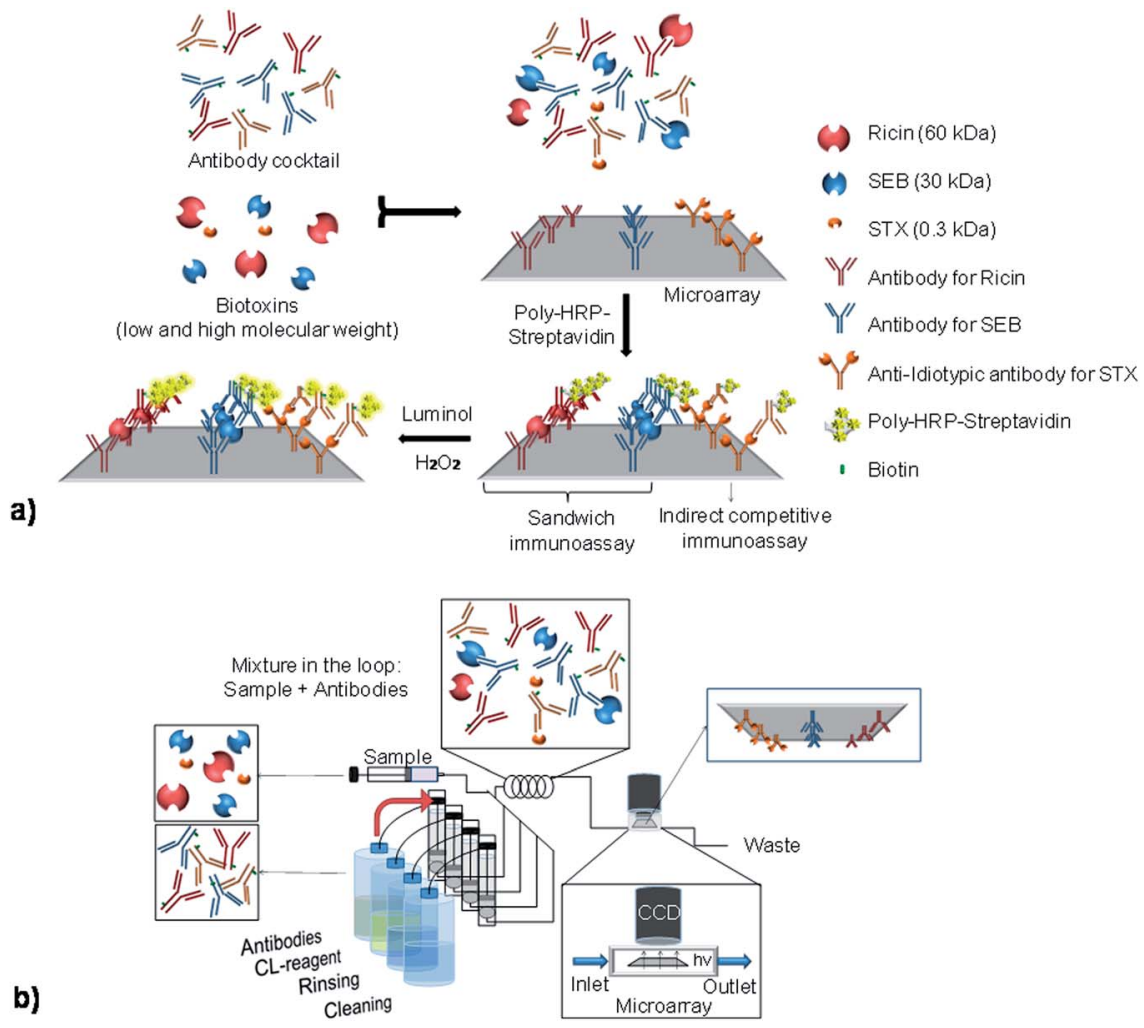

Fig. 1 Schemes representing the sandwich and indirect competitive immunoassays in the same microarray for the MCR3 analysis. (a) The sandwich immunoassays used for ricin and SEB detection are combined with the indirect competitive immunoassays for STX detection in the same microarray chip by using anti-idiotypic antibodies. (b) The sample (biotoxins) and the biotinylated antibodies are injected at the same time into the loop, captured in the antibody microarray and detected by chemiluminescence reaction between luminol and hydrogen peroxide catalyzed by poly(horseradish peroxidase)-streptavidin.

driven to the microarray surface, where the reactions take place and the signal is registered. The spots on the microarray are identified by their location on the recorded image. The antibodies are spotted on a defined location and order, which allows the fast recognition of the correspondent system.

\section{Assay optimization}

In order to develop a multi-analyte detection system for biotoxins, it is necessary to optimize the parameters which influence the assay sensitivity. Antibody selection and concentration, interaction time, continuous/stopped flow, sequential/parallel addition, addition rate and reaction volume are the main parameters to be optimized. The optimization was exemplarily performed for ricin detection. $R$. communis agglutinin is a $120 \mathrm{kDa}$ lectin with about $90 \%$ sequence identity to ricin and was chosen for the initial tests due to its lower toxicity. ${ }^{3}$ Different antibodies were available for ricin detection that cross-react with $R$. communis agglutinin, including monoclonal (mAb R109 and mAb R21) and a biotinylated monoclonal detection antibody (mAb R18).

To enhance the assay sensitivity, the conventional label based on enzyme horseradish peroxidase-streptavidin (SA-HRP) conjugates was replaced by poly(horseradish peroxidase)-streptavidin (SA-PolyHRP40) conjugates. SA-PolyHRP40 is a supramolecular complex composed of five identical covalent HRP homopolymer blocks covalently coupled to streptavidin molecules. For the SA-PolyHRP40, there is an average of 200 monomer HRP molecules per complex unit. ${ }^{46}$ The comparison of both labels was performed using a sandwich ELISA immunoassay with TMB substrate, monoclonal capture antibody R109 and monoclonal detection antibody R18. The calibration curves for SA-HRP and SA-PolyHRP40 (available at the ESI, S2 $\dagger$ ) were obtained in the range of 0 to $1000 \mu \mathrm{g} \mathrm{L} \mathrm{L}^{-1}$ of agglutinin. The SA-PolyHRP40 curve showed higher sensitivity with a working range saturating at $100 \mu \mathrm{g} \mathrm{L}{ }^{-1}$, where the SA-HRP curve only started its working range with 10 times lower absorbance. PolyHRP40 conjugates quantitatively delivered a large number of signal-generating enzyme molecules per one bound analyte molecule, resulting in a considerable signal enhancement. As a result, the assay using SA-PolyHRP40 produces higher sensitivity and therefore it was chosen for the next optimizations. For all further measurements ricin has been used instead of agglutinin, which is recognized by the same set of antibodies with high affinity. ${ }^{47}$

To combine sandwich and competitive immunoassay principles in the flow system, it is important to meet the requirements of the individual assays. The competitive immunoassay requires the pre-incubation of the antibody and the antigen prior to the detection with parallel addition on the microarray. For the sandwich assay, the pre-incubation is not necessary, but it can also be favorable for the detection. In order to investigate 
the effects of the sequential or parallel addition on the assay performance, four conditions were compared for ricin: (I) sequential addition of reactants (ricin and biotinylated detection antibody) at $1 \mu \mathrm{L} \mathrm{s}^{-1}$ with $10 \mathrm{~s}$ of interaction time (duration: $1 \mathrm{~h} 15 \mathrm{~min}$ ), (II) parallel addition in continuous flow at $1 \mu \mathrm{L} \mathrm{s}^{-1}$ (duration: $26 \mathrm{~min}$ ), (III) parallel addition with pre-incubation step of the detection antibody and the ricin for $1 \mathrm{~min}$ in the MCR3 loop, injecting $50 \mu \mathrm{L}$ of sample at $1 \mu \mathrm{L} \mathrm{s}^{-1}$ with $20 \mathrm{~s}$ of incubation time (duration: $34 \mathrm{~min}$ ) and (IV) parallel addition with pre-incubation step, injecting $5 \mu \mathrm{L}$ of sample at $1 \mu \mathrm{L} \mathrm{s}^{-1}$ with $10 \mathrm{~s}$ of incubation time (duration: $1 \mathrm{~h} 15 \mathrm{~min}$ ). The assay was tested with two different capture antibodies, R109 and R21, and the biotinylated mAb R18 as the detection antibody. The results (see ESI, S3†) indicated that the parallel addition produces faster results with higher chemiluminescence signal for all conditions in comparison to the sequential addition. The evaluation of the three conditions using parallel addition (II-IV) indicated better performance with the use of stopped-flow principle (III and IV) as an approximation to a stationary system. In this case, a defined volume is pumped into the chip and remains there for a certain time. The method (IV) results in higher CL signal (8421 a.u. for R109 and 7827 a.u. for R21) than the method (III) with 2988 a.u. for R109 and 3756 a.u. for R21, indicating that a lower unit volume in a shorter time interaction leads to higher signals. Although the incubation time for the method IV is half of the method III, the additional interaction time for the program IV was 41 minutes. This means that the ricin molecules had more time to come in contact with the immobilized antibodies and interact with them, justifying the higher CL-signal intensity. It is also observed that the monoclonal R109 antibody produces higher CL signal in comparison to the R21 antibody. The results showed that the use of parallel addition with stopped flow principle is favorable to enhance the assay sensitivity for the sandwich assay and it indicates the promising combination with the competitive assay in the multiplex system.

The influence of the sample volume, flow rate and interaction time on the CL signal was also investigated and the results are described in the ESI $(\mathrm{S} 4 \dagger)$. The injected volume on the microarray was varied from 5 to $50 \mu \mathrm{L}$ and the CL signal was compared. The signals for $5 \mu \mathrm{L}$ (57681 a.u. for R109 and 54483 a.u. for R21) and $50 \mu \mathrm{L}$ (49912 a.u. for R109 and 48150 a.u. for R21) showed a maximum decrease in the CL signal intensity of $13.5 \%$. Nevertheless, the assay time is more than two times faster for $50 \mu \mathrm{L}$ than for $5 \mu \mathrm{L}$. Therefore, the volume of $50 \mu \mathrm{L}$ was chosen. The flow rate optimization showed that $10 \mu \mathrm{L} \mathrm{s}^{-1}$ was the best compromise between assay time and CL signal, reducing even more the analysis time to $18 \mathrm{~min}$. Table 2 summarizes the final optimized parameters, indicating preincubation of biotoxins and antibodies for $1 \mathrm{~min}$ in the loop, injection of $50 \mu \mathrm{L}$ units of the mixture by a stopped-flow principle at a flow rate of $10 \mu \mathrm{L} \mathrm{s}^{-1}$ with interaction times of $10 \mathrm{~s}$.

\section{Calibration curves of the biotoxins}

The optimized program enabled the measurement of calibration curves for ricin using the capture antibodies R21 and R109
Table 2 Optimized measuring parameters

\begin{tabular}{ll}
\hline Parameters & Optimized values \\
\hline Label & Poly(horseradish peroxidase)-streptavidin \\
Time of pre-incubation & $1 \mathrm{~min}$ \\
Injected volume & $50 \mu \mathrm{L}$ \\
Flow rate & $10 \mu \mathrm{L} \mathrm{s}^{-1}$ \\
Interaction time & $10 \mathrm{~s}$ \\
Total duration & $18 \mathrm{~min}$
\end{tabular}

on the flow analysis platform MCR3. For this purpose, both antibodies were immobilized together on different microarrays for each concentration and a concentration range of 1 to 2000 $\mu \mathrm{g} \mathrm{L}^{-1}$ of ricin was measured. Fig. 2a shows that the capture
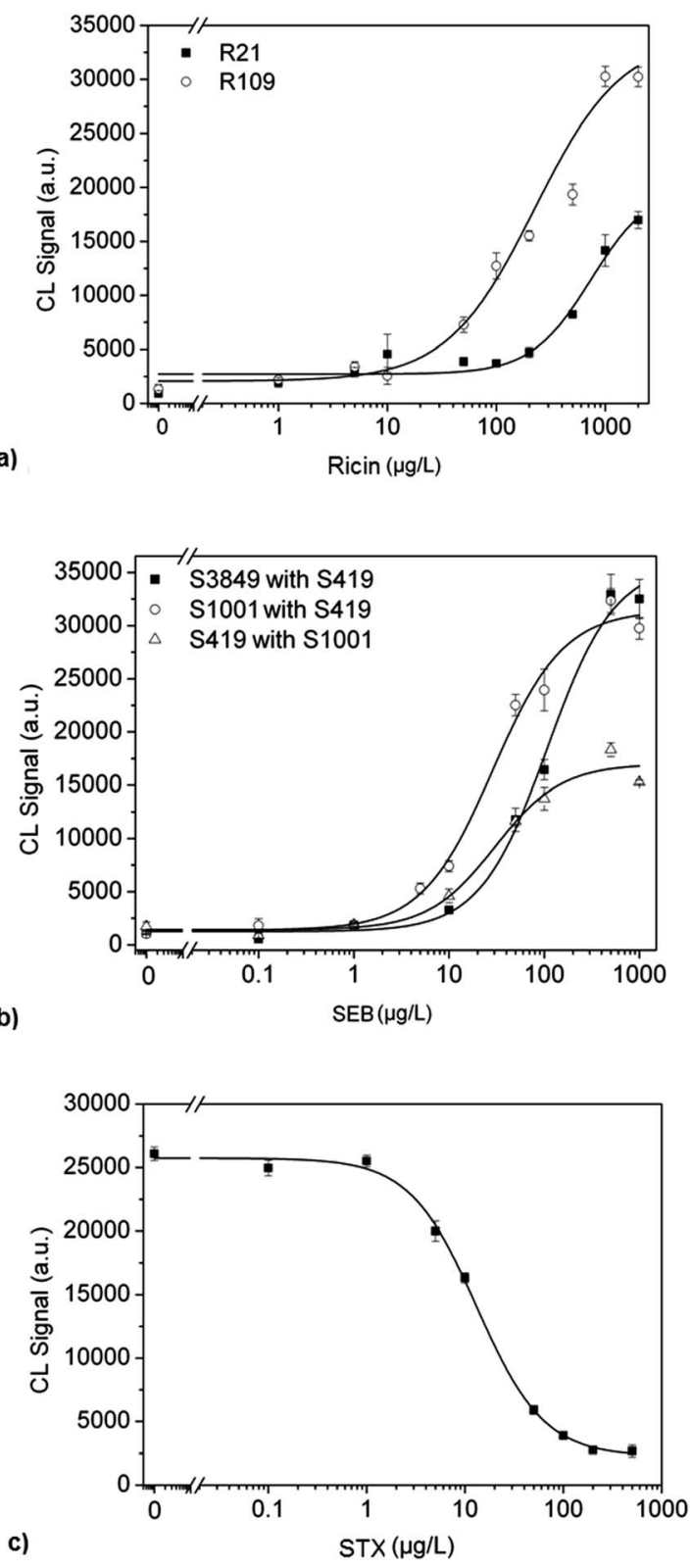

Fig. 2 Calibration curves. Calibration curves separately obtained for ricin, SEB and STX. Different combination of antibodies were used for ricin and SEB. 
antibody R109 provides higher CL signals, to an average factor of 2-3 in comparison to the R21. The affinity of R109 to ricin appears to be higher, because the midpoint $\left(224.1 \mu \mathrm{g} \mathrm{L}^{-1}\right)$ and the work area (from 48.8 to $1029.8 \mu \mathrm{g} \mathrm{L}^{-1}$ ) are shifted to lower concentrations compared to R21 with a midpoint at $740.7 \mu \mathrm{g}$ $\mathrm{L}^{-1}$ and a work area between 151.6 and $1589.7 \mathrm{~g} \mathrm{~L}^{-1}$. Therefore, R109 antibody was used for the multiplex analysis.

Staphylococcal enterotoxin B is similarly to ricin a high molecular weight toxin and is detected in a heterogeneous sandwich ELISA. Therefore, the measurement program optimized for ricin was also used for the SEB detection. The calibration curve was produced by varying the concentration from 0 to $1000 \mu \mathrm{g} \mathrm{L}^{-1}$. For the detection of SEB three monoclonal antibodies were used: S3849, S1001 and S419. These antibodies were tested as capture and detection antibodies, resulting in 6 combinations in a sandwich format. Fig. 2b shows three combinations that yielded the most sensitive calibration curves. The antibody pair S3849 and S419 provided the highest CL signals. However, the sensitivity of this antibody pair is lower because the midpoint is $108.2 \mu \mathrm{g} \mathrm{L}^{-1}$ and the working area is from 31.2 to $375.5 \mu \mathrm{g} \mathrm{L}^{-1}$ compared to the other two antibody pairs, which are shifted to higher levels. The other two pairs S1001 with S419 and S419 with S1001 showed work areas as well as the midpoint in the same order. However, the antibody pair S1001with S419 has a higher CL signal intensity by a factor of 2 for each calibration point and also a lower detection limit, 0.1 $\mu \mathrm{g} \mathrm{L}^{-1}$. Thus, the antibody pair S1001 with S419 was chosen for the following multiplex measurements.

STX detection was performed with anti-idiotypic antibodies in an indirect competitive ELISA format. The antibodies were immobilized at $0.5 \mathrm{~g} \mathrm{~L}^{-1}$ on the glass surface of the chip. The saxitoxin calibration curve was obtained for the concentration range of 0 to $500 \mu \mathrm{g} \mathrm{L}^{-1}$, using the same optimized conditions for ricin. Fig. 2c shows the calibration curve with the midpoint at $13.2 \mu \mathrm{g} \mathrm{L}^{-1}$ and the detection limit at $1.4 \mu \mathrm{g} \mathrm{L}^{-1}$. The specified operating range is between 3.2 and $54.1 \mu \mathrm{g} \mathrm{L}^{-1}$. The use of anti-idiotypic antibodies is the first step for the successful combination of the two assay principles into one antibody microarray platform. It also has the advantage of using the same conditions for the immobilization, incubation and blocking steps.

\section{Combination of sandwich and indirect competitive assays on the same microarray}

Microarrays were produced by immobilization of capture antibody anti-ricin (R109) and anti-SEB (S1001) together with the anti-idiotypic antibodies. The calibration curves for the biotoxins were measured three times independently and obtained from 0 to $500 \mu \mathrm{g} \mathrm{L}^{-1}$ with additional concentrations for SEB $\left(1000 \mu \mathrm{g} \mathrm{L}^{-1}\right)$ and for ricin $\left(1000\right.$ and $\left.2000 \mu \mathrm{g} \mathrm{L}^{-1}\right)$. The curves are depicted in the Fig. 3.

The calibration data of the multiplexed measurements are listed in Table 3. To compare the three calibration curves, the coefficient of variation (CV) was calculated from the midpoint of the three multiplex calibration curves. The variation coefficient was $13.9 \%$ for ricin, $9.3 \%$ for SEB and $28.0 \%$ for STX. The

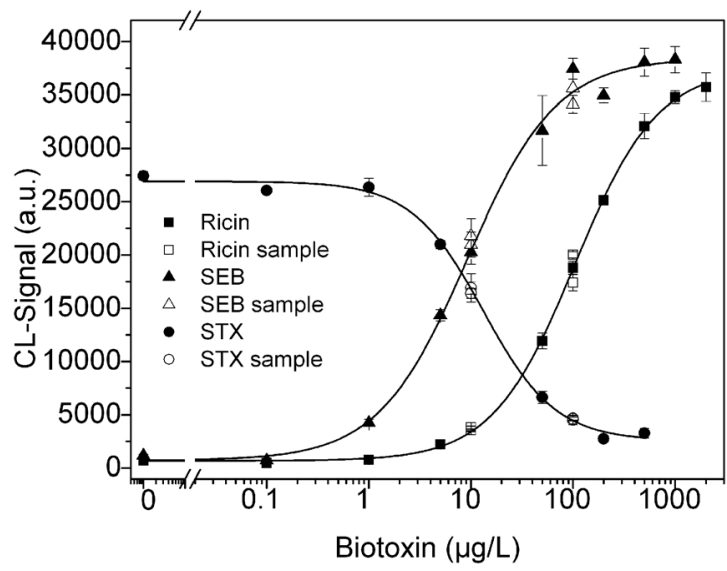

Fig. 3 Multiplex calibration curve. Calibration curve were simultaneously obtained for ricin, SEB and STX performed on the same chip for each concentration. The sample also consisted of a mixture of the biotoxins.

detection limit obtained for STX is similar to the LOD described by Szkola et al. ${ }^{29}$ in an indirect microarray. This indicates the successful adaptation to the competitive assay.

Furthermore, the LOD for ricin and SEB are as low as the available microarrays for this biotoxins, as shown in the Table 1.

Reproducibility measurements were performed using a new microarray chip per analysis and different biotoxin concentrations: ricin $500 \mu \mathrm{g} \mathrm{L}^{-1}$, SEB $100 \mu \mathrm{g} \mathrm{L}^{-1}$ and saxitoxin $10 \mu \mathrm{g} \mathrm{L}^{-1}$. The results of the four measurements indicated stable CL signals with low standard deviation: $1.8 \%$ for ricin, $4.1 \%$ for SEB and $3.5 \%$ for STX. These results prove that a parallel measurement of biotoxins with different molecular weight is possible.

For the determination of recovery rates (Table 4), the biotoxins were first calibrated simultaneously, followed by sample measurement. The samples were plotted together with the calibration curve (Fig. 3). The CL signals of the sample agree with the calibration curves. Table 3 lists the values of the recovery rates measured. An average recovery rate for ricin was $11.1 \mu \mathrm{g} \mathrm{L}^{-1}$ for the sample with a concentration of $10 \mu \mathrm{g} \mathrm{L}^{-1}$ and $100.9 \mu \mathrm{g} \mathrm{L}^{-1}$ for the sample with $100 \mu \mathrm{g} \mathrm{L}^{-1}$. Comparable good recoveries were obtained for SEB with $11.1 \mu \mathrm{g} \mathrm{L}^{-1}$ and $92.5 \mu \mathrm{g}$ $\mathrm{L}^{-1}$ and for STX with $10.2 \mu \mathrm{g} \mathrm{L}^{-1}$ and $94.5 \mu \mathrm{g} \mathrm{L}^{-1}$, even for the concentrations out of the working range between 20 and $80 \%$. The spiked sample of water is an example of matrix, which can assume different types in real analysis. Water and food are cited as the most probable, but other matrices can also be analyzed, such as contaminated soil. Real samples may bring some

Table 3 Multiplex calibration of ricin, SEB and STX

\begin{tabular}{lllll}
\hline Toxin & IC50 $\left(\mu \mathrm{g} \mathrm{L}^{-1}\right)$ & WR $(20-80 \%)\left(\mu \mathrm{g} \mathrm{L}^{-1}\right)$ & LOD $\left(\mu \mathrm{g} \mathrm{L}^{-1}\right)$ & CV $(\%)$ \\
\hline Ricin & $93.7 \pm 13.1$ & $23.8 \pm 2.7-301.9 \pm 43.8$ & $2.9 \pm 3.1$ & 13.9 \\
SEB & $8.7 \pm 0.8$ & $1.7 \pm 0.4-48.6 \pm 15.2$ & $0.1 \pm 0.1$ & 9.3 \\
STX & $10.1 \pm 2.8$ & $2.6 \pm 1.5-37.2 \pm 3.3$ & $2.3 \pm 1.7$ & 28.0
\end{tabular}


Table 4 Recoveries of ricin, SEB and STX

\begin{tabular}{|c|c|c|c|c|c|c|}
\hline$\frac{\text { Amount }}{\left(\mu g \mathrm{~L}^{-1}\right)}$ & \multicolumn{6}{|l|}{ Recovery } \\
\hline 10 & 10.7 & 106.6 & 10.6 & 106.5 & 9.8 & 98.6 \\
\hline 10 & 11.5 & 115.3 & 11.6 & 116.3 & 10.6 & 105.9 \\
\hline 100 & 114.1 & 114.1 & 71.4 & 71.4 & 92.5 & 92.5 \\
\hline Average & $100.9 \pm 18.6$ & $100.9 \pm 18.6$ & $92.5 \pm 29.9$ & $92.5 \pm 29.9$ & $94.5 \pm 3.2$ & $94.5 \pm 3.2$ \\
\hline
\end{tabular}

difficulties, which prevent the directly application in the MCR3. Water samples, for example, must be filtered in order to avoid blocking of the microfluidic channel and solid samples should be digested and brought to a liquid form to inject in the machine. Although the antibodies are highly specific for the toxins, cross-reactions may also be considered.

\section{Conclusions}

For the first time, an antibody microarray chip was produced to detect proteotoxins and small biotoxin, combining sandwich and indirect competitive immunoassay principles. The combination of both assays on one microarray was possible by the use of anti-idiotypic antibodies, which mimic the structure of STX and is also recognized by the detection $\mathrm{Ab}$. The chemiluminescence signal was amplified by using polyHRP40, providing an assay with comparable or lower detection limits than the available microarrays for the biotoxins. The described microarray platform proved to be a promising tool for biowarfare applications, not only for the mentioned toxins but for any other relevant toxin. This work opens the possibility to produce parallel detection arrays for large and small analytes in different applications, as highly required to food ${ }^{48-50}$ and water ${ }^{51}$ analysis.

\section{Acknowledgements}

The authors would like to thank K. Campbell and C. Elliott from Queen's University in Ireland, for providing STX. We acknowledge the company Huntsman (Salt Lake City, USA) for offering the Jeffamine ED-2003 polyetheramine. We also kindly thank S. Wiesemann and R. Hoppe from the Institute of Hydrochemistry's workshop for producing the plastic covers.

\section{Notes and references}

1 H. Russmann, Gesundheitsschutz, 2003, 46, 989-996.

2 R. Franz, Defense against toxin weapons, Medical Aspects of Chemical and Biological Warfare, Textbook of Military Medicine, Washington DC, 1997.

3 S. Worbs, K. Köhler, D. Pauly, M. A. Avondet, M. Schaer, M. B. Dorner and B. G. Dorner, Toxins, 2011, 3, 1332-1372.

4 W. Burrows and S. Renner, Environ. Health Perspect., 1999, 107, 975-984.
5 B. Katzin, Proteins: Struct., Funct., Bioinf., 1991, 10, 251-259. 6 CDC-10.20.2013, http://www.bt.cdc.gov/agent/agentlistcategory.asp.

7 WWCA-10.20.2013, http://www.opcw.org/chemicalweaponsconvention/download-the-cwc.

8 W. Catterall, Neuron, 2000, 26, 13-25.

9 E. Schantz and E. Johnson, Microbiol. Rev., 1992, 56, 80-99.

10 H. Tanino, T. Nakata, T. Kaneko and Y. Kishi, J. Am. Chem. Soc., 1977, 99, 2818-2819.

11 E. Schantz, Ann. N. Y. Acad. Sci., 1960, 90, 843-855.

12 H. D. Raj and M. S. Bergdoll, J. Bacteriol., 1969, 98, 833-834.

13 A. Brosnahan and P. Schlievert, FEBS J., 2011, 278, 46494667.

14 N. Balaban and A. Rasooly, Int. J. Food Microbiol., 2000, 61, 110.

15 A. Lakoff and S. J. Collier, Biosecurity interventions: Global health and security in question, Columbia University Press, New York, 2012.

16 J. Gooding, Anal. Chim. Acta, 2006, 559, 137-284.

17 H. Bates and H. Rapoport, J. Agric. Food Chem., 1975, 23, 237-239.

18 R. Manger, L. Leja, S. Lee, J. Hungerford and M. Wekell, Anal. Biochem., 1993, 214, 190-194.

19 J. Jellett, L. Marks, J. Stewart, M. Dorey, W. Watson-Wright and J. Lawrence, Toxicon, 1992, 30, 1143-1156.

20 S. R. Kalb and J. R. Barr, Anal. Chem., 2009, 81, 2037-2042.

21 S. Kull, D. Pauly, B. Störmann, S. Kirchner, M. Stämmler, M. B. Dorner, P. Lasch, D. Naumann and B. G. Dorner, Anal. Chem., 2010, 82, 2916-2924.

22 T. McGrath, C. Elliott and T. Fodey, Anal. Bioanal. Chem., 2012, 403, 75-92.

23 E. Ezan, E. Duriez, F. Fenaille and F. Becher, Functional Assays for Ricin Detection, in Detection of Biological Agents for the Prevention of Bioterrorism, ed. J. Banoub, Springer Netherlands, Dordrecht, 2011, pp. 131-147.

24 W. Lian, D. H. Wu, D. V. Lim and S. G. Jin, Anal. Biochem., 2010, 401, 271-279.

25 O. G. Weingart, O. G. Weingart, H. Gao, F. Crevoisier, F. Heitger, M. A. Avondet and H. Sigrist, Sensors, 2012, 12, 2324-2339.

26 E. J. Cho, J. R. Collett, A. E. Szafranska, A. E. Szafranska and A. D. Ellington, Anal. Chim. Acta, 2006, 564, 82-90. 
27 M. Huebner, K. Wutz, A. Szkola, R. Niessner and M. Seidel, Anal. Sci., 2013, 29, 461-466.

28 J. Cooper, N. Yazvenko, K. Peyvan, K. Maurer, C. R. Taitt, W. Lyon and D. L. Danley, PLoS One, 2010, 5, e9781.

29 A. Szkola, K. Campbell, C. T. Elliott, R. Niessner and M. Seidel, Anal. Chim. Acta, 2013, 787, 211-218.

30 S. E. McNamee, C. T. Elliot, P. Dalahnt and K. Campbell, Environ. Sci. Pollut. Res., 2013, 20, 6794-6807.

31 D. Pauly, S. Kirchner, B. Stoermann, T. Schreiber, S. Kaulfuss, R. Schade, R. Zbinden, M. Avondet, M. B. Dorner and B. Dorner, Analyst, 2009, 134, 2028-2039.

32 M. Seidel and R. Niessner, Anal. Bioanal. Chem., 2008, 391, 1521-1544.

33 S. Oswald, X. Y. Z. Karsunke, R. Dietrich, E. Märtlbauer, R. Niessner and D. Knopp, Anal. Bioanal. Chem., 2013, 405, 6405-6415.

34 F. S. Ligler, C. R. Taitt, L. C. Shriver-Lake, K. E. Sapsford, Y. Shubin and J. P. Golden, Anal. Bioanal. Chem., 2003, 377, 469-477.

35 Y. Fang, A. G. Frutos and J. Lahiri, Langmuir, 2003, 19, 15001505.

36 M. Hartmann, M. Schrenk, A. Doettinger, S. Nagel, J. Roeraade, T. O. Joos and M. F. Templin, Clin. Chem., 2008, 54, 956-963.

37 S. L. Lim, H. Ichinose, T. Shinoda and H. Ueda, Anal. Chem., 2007, 79, 6193-6200.

38 V. Parro, G. de Diego-Castilla, J. A. Rodriguez-Manfredi, L. A.Rivas, Y. Blanco-Lopez, E. Sebastian, J. Romeral, C. Compostizo, P. L. Herrero, A. Garcia-Marin, M. Moreno-
Paz, M. Garcia-Villadangos, P. Cruz-Gil, V. Peinado, J. Martin-Soler, J. Perez-Mercader and J. Gomez-Elvira, Astrobiology, 2011, 11, 15-28.

39 P. Fernández-Calvo, L. A. Rivas, C. Naeke, M. GarcíaVilladangos, J. Gómez-Elvira and V. Parro, Planet Space Sci., 2006, 54, 1612-1621.

40 A. Akkoyun, V. Kohen and U. Bilitewski, Sens. Actuators, B, 2000, 70, 12-18.

41 Y. Pan, S. C. Yuhasz and L. M. Amzel, FASEB J., 1995, 9, 4349.

42 D. Pauly, S. Worbs, S. Kirchner, O. Shatohina, M. B. Dorner and B. G. Dorner, PLoS One, 2012, 7, e35360.

43 A. Wolter, R. Niessner and M. Seidel, Anal. Chem., 2007, 79, 4529-4537.

44 V. Langer, R. Niessner and M. Seidel, Anal. Bioanal. Chem., 2011, 399, 1041-1050.

45 K. Kloth, R. Niessner and M. Seidel, Biosens. Bioelectron., 2009, 24, 2106-2112.

46 D. Li, Y. Ying, J. Wu, R. Niessner and D. Knopp, Microchim. Acta, 2013, 180, 711-717.

47 D. Pauly, M. Dorner, X. Zhang, A. Hlinak, B. Dorner and R. Schade, Poult. Sci., 2009, 88, 281-290.

48 P. D. Patel, Trends Anal. Chem., 2002, 21, 96-115.

49 E. C. Alocilja and S. M. Radke, Biosens. Bioelectron., 2003, 18, 841-846.

50 L. D. Mello and L. T. Kubota, Food Chem., 2002, 77, 237-256.

51 S. D. Richardson and T. A. Ternes, Anal. Chem., 2005, 77, 3807-3838. 